\title{
Conservation implications of the drinking habits of Black-cheeked Lovebirds Agapornis nigrigenis in Zambia
}

\author{
LOUISE S. WARBURTON and MICHAEL R. PERRIN
}

\section{Summary}

Since 1950, the annual rainfall in the habitat of Black-cheeked Lovebirds Agapornis nigrigenis has decreased, increasing dependence on artificial water supplies. In this study, the seasonal water requirements and drinking behaviour of the lovebirds in their natural habitat were investigated. During the dry season, lovebirds drank at the same water-point in the early morning and late afternoon. Flock sizes of birds at drinking sites ranged from 1 to 175 individuals. Birds from one locale all drank at the same waterhole. Black-cheeked Lovebirds were vigilant and highly cautious drinkers that did not drink at waterholes when disturbed by humans or livestock. The implications for conservation of the species are discussed. Since water availability is a limiting factor for the Black-cheeked Lovebird, gradual desiccation of its habitat has caused the reduction of its small distributional range. Because of increasing dependence on artificial water supplies in a highly localized distribution the priority for conservation management of the species must be creating and maintaining water resources with minimal external disturbance.

\section{Introduction}

Daily water requirements of birds are met by three sources: free water from standing surface water such as rain and dew; preformed water contained in food and metabolic water produced by the oxidation of organic compounds containing hydrogen (Robbins 1993). Water intake rates increase with ingestion of dry seeds (Calder 1981) such that free-ranging birds can habituate to stressful environments. Hence, physiological studies of captive birds (e.g. Budgerigar Melopsittacus undulatus; Cade and Dybas 1962) aid our understanding of the ecological requirement of water in natural habitats (Robbins 1993). Parrots in the wild consume more food, with lower nutrient quality, than sedentary birds in captivity (Klasing 1998). Many parrots are specialist feeders of dry foods, particularly seeds, containing little preformed water but considerable metabolic water. Most parrots, particularly those whose diet comprises mainly herb and grass seeds, are obligate daily drinkers and thus highly dependent on sources of free-standing water (Fisher et al. 1972, del Hoyo et al. 1997). Although little is known about the ecological requirements of lovebirds in the wild, the white eye-ringed species (A. fischeri, A. personatus, A. lilianae and A. nigrigenis) and Rosy-faced Lovebird A. roseicollis are known to concentrate around water sources (Moreau 1945, 1948, Button 1953, Forshaw 1989, Moyer 1995, Fry et al. 1998).

In this study, the drinking habits of wild Black-cheeked Lovebirds Agapornis nigrigenis were investigated. This small parrot (130-140 mm long, 39 g; Maclean 1988, Warburton 2001a, Warburton 2002) has the most restricted distribution of any 
African psittacine species, with a core range of approximately $2,500 \mathrm{~km}^{2}$ (Dodman 1995, Dodman et al. 2000). It is primarily found in mopane Colophospermum mopane woodland, but moves into adjoining habitats, such as riverine vegetation and agricultural areas, to forage and drink. Since grains dominate the Black-cheeked Lovebird's diet (Warburton 2003, Warburton and Perrin in prep.), it is highly dependent on water for its survival. This was shown by Dodman (1995) and Dodman et al. (2000) who recorded Black-cheeked Lovebird population densities along river catchments in Zambia at the height of the 1994 dry season. Lovebird concentrations were greatest in the mid-Machile and mid-Sichifulo river catchments close to mopane woodland that contained permanent water sources. Regions without surface water, even those within the core range of suitable habitat, such as Bovu and Sinde catchments, contained no lovebirds.

The apparent non-recovery of the species following population decline is correlated with the decrease in availability of free water (Dodman 1995, Dodman et al. 2000). In addition to this environmental problem, birds were trapped extensively and routinely from 1908 until a Zambian trade ban was implemented on wild-caught birds in 1930 . However, trade appeared to continue until the 196os (Dodman 1995). Currently, the total population is estimated at 10,000 birds (Dodman 1995, Dodman et al. 2000), and the species is classified as Vulnerable (BirdLife International 2000).

The aim of this study was to determine the drinking habits of Black-cheeked Lovebird in its natural range throughout the year. Drinking behaviour was documented over a 22-month observation period. It was necessary to determine water requirements to elucidate implications for the conservation of the species.

\section{Study area}

Zambia is a landlocked country in southern-central Africa. Black-cheeked Lovebirds inhabit the driest region of Zambia, a vast plain area, at 914-1,341 $\mathrm{m}$ a.s.l., intersected by the floodplains and tributaries of the Zambezi and Kafue rivers within the Southern and Western Provinces. The dominant vegetation within the range of Black-cheeked Lovebirds is mopane Colophospermum mopane woodland. The lovebird's range is marked by two distinct seasons: a rainy season, usually from November to March, with a mean annual rainfall of $600 \mathrm{~mm}$ (NPWS/JICA 1999), and a long dry season from April to November, with April being a transition month. The coldest month is July (mean maximum temperature $22-28^{\circ} \mathrm{C}$, mean minimum temperature $5-7^{\circ} \mathrm{C}$ ), while October is the hottest month (mean maximum $31-35^{\circ} \mathrm{C}$, mean minimum $15-18^{\circ} \mathrm{C}$ ) (NPWS/JICA 1999). Black-cheeked Lovebirds occur in two distinct but adjacent geographical ranges between $15^{\circ}$ and $17^{\circ} \mathrm{S}$ and $24^{\circ}$ and $26^{\circ} \mathrm{E}$ (Dodman 1995, Dodman et al. 2000). The northern population occurs along the Nanzhila river, largely confined to Kafue National Park and surrounding Game Management Areas. The southern population is centred around the Machile and Sichifulo rivers, with the Simatanga river to the north and Ngweze river in the south forming the limits of the species range. Few artificial (man-made) water sources are available to the northern subpopulation. This contrasts with the southern subpopulation whose range encompasses subsistence agricultural areas where local people make small dams in riverbeds, dig wells and shallow pools along otherwise dry river courses, and occasionally fill troughs for cattle. The lovebird's range suffers serious water shortages from June to December as all rivers in the region, with the exception of 
the Zambezi and Kafue, are ephemeral (L. Warburton pers. obs.). The only other naturally occurring water source is scattered shallow pools, few of which last through the dry season (L. Warburton pers. obs.). The distribution of surface water is irregular, and scarce, with its abundance and quality depending primarily on the previous rainy season.

\section{Methods}

Rainfall data for the period 1950-1995 were collected from two meteorological stations in south-west Zambia (Choma and Livingstone) from the Meteorological Department in Livingstone, and analysed using linear regression to test for a pattern of reduced rainfall over the period (following Dodman 1995 and Dodman et al. 2000 who used data from Sesheke, Mulobezi, Machile and Livingstone stations).

Black-cheeked Lovebird drinking activity was studied during 22 months (MayDecember 1998; April-December 1999; February-May 2000) of intensive fieldwork in south-west Zambia using Swift $8 \times 42$ binoculars and a Kowa $\times 10$ telescope. Locations were recorded using a Garmin 12XL Global Positioning System (GPS).

Drinking sites were located by following lovebirds early in the morning (after roost-site departure) and in late afternoon, with opportunistic watches at areas with suitable surface water, and by interviewing local inhabitants. When lovebirds drank, the time, flock size, behaviour (e.g. preening, perching, vigilance, socializing), presence of other species, number of sips, and pool location and type were recorded.

The lovebirds used a variety of water sources categorized as the following major types: 'mopane pools' (natural depressions within the mopane woodland habitat where water collected, but usually dried up by mid-July); 'river pools' (pools found within river courses or drainage channels); 'plain pools' (pools found within a grassland plain habitat, usually adjoining mopane woodland and not part of a river drainage system); and 'artificial' pools (all water sources which were available to lovebirds due to human intervention).

Kruskal-Wallis tests were used to test for significant differences in flock sizes between morning and afternoon drinking sessions. Given the irregularity of the surface water distribution, both spatially and temporally, it was impossible to devise an index of resource availability.

\section{Results}

Rainfall analysis

Annual rainfall (recorded for the Livingstone and Choma areas) decreased (Figure 1 ) from a mean of $740 \pm 23 \mathrm{~mm}$ in $1950-1970$ to a mean of $676 \pm 30.4 \mathrm{~mm}$ in the 1970s-1990s. From simple regression analysis (Figure 1 ) it can be seen that rainfall declined at a rate of about $5 \mathrm{~mm}$ a year. The major consequence for the lovebirds was a reduction in available surface water sites during the dry season and a decline in underground water table levels. Local people had to dig deeper wells which became inaccessible to the lovebirds.

Black-cheeked Lovebirds were observed drinking from water pools on 807 occasions, mostly during the dry season. During the rains, lovebirds drank from whatever water source was available, usually as individuals without pre- and post-drinking 


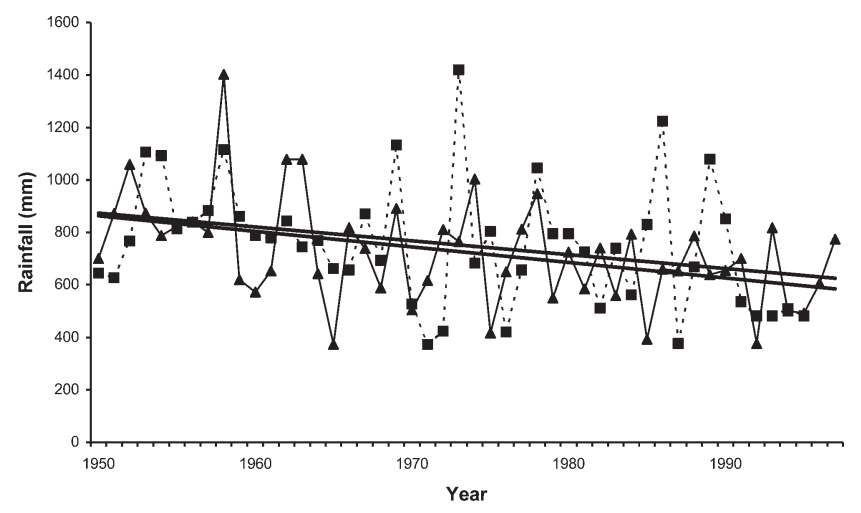

Figure 1. Total annual rainfall recorded at Choma $(\boldsymbol{\square})$ and Livingstone $(\boldsymbol{\Delta})$ meteorological stations in south-west Zambia between 1950 and 1997. Unbroken lines are represented by $y=-5.9289 x+868.91$, with regression coefficient $\left(r^{2}\right)=0.1706$ for Livingstone and $y=-5.2859 x+878.15$, with regression coefficient $\left(r^{2}\right)=0.0902$ for Choma.

social rituals. After rainstorms, birds drank from water collected on foliage and in depressions along tree branches, as well as from puddles and temporary water pans.

In the lovebird's northern range there was little human activity, so all pools were formed naturally along watercourses or were natural depressions in mopane woodland or on grassland plains. In the south, however, the lovebirds were more dependent on man-maintained or man-made water resources, particularly during the dry season. Lovebirds drank from wells dug in riverbeds, water-filled wooden livestock troughs, small dams and wider depressions dug in sandy riverbeds. Where lovebirds used wells and troughs no other surface water was available. However, the birds did not use any water sources subject to human or livestock disturbance, wells with a steep access, or pools without a perching position within $20 \mathrm{~m}$ of the water's edge. Mean distance from roosts to nearest water sources utilized by the lovebirds, during the dry season, was $4.9 \pm 1.34 \mathrm{~km}$, ranging between 1.94 and $7.85 \mathrm{~km}(n=4)$.

Although most birds drank during two daily peaks of activity, post-sunrise and pre-sunset, some birds drank throughout the day (Figure 2). Most lovebirds drank twice daily, as demonstrated by natural colour-morphed birds, one yellow and three light green birds, that drank at the same pools twice daily on frequent occasions over a 12-month period.

Numbers of lovebirds drinking at each water pool varied spatially, probably reflecting local lovebird abundance and distance to the next drinking site. Generally, all lovebirds from a local area drank at the same water source, even when it was not the most centralized pool between various roost sites. This was ascertained by surveying all the water sources in the locality for lovebird activity, and observing the flight-paths of birds leaving and returning to roosts.

During the mid-to-late dry season the more isolated water sources appeared to attract birds from a greater surrounding area. The largest number of lovebirds observed drinking at a single waterhole was approximately 800 at Mabiya Pools in south Kafue National Park, and where approximately 300 and 250 individuals drank at separate pools $1.3 \mathrm{~km}$ apart in the mid-Machile river region. Other pools across the species range attracted far fewer lovebirds $(\bar{x}=24 \pm 3.2, n=74$ observations of 24 different pools) at the height of the dry season, reflecting localized lovebird abundance. 


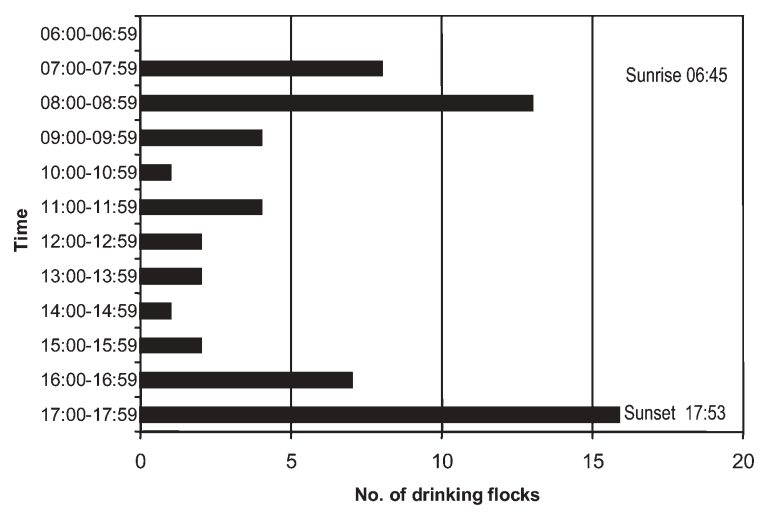

Figure 2. Average number of Black-cheeked Lovebird drinking flocks observed per hour during six all-day pool-watches at the study site in south-west Zambia along the Machile and Sichifulo rivers during February-April 2000.

Most flocks ( $77 \%$ ) of lovebirds observed drinking consisted of $1-10$ birds, although a few comprised up to 175 birds. Overall $90 \%$ of flocks comprised $1-20$ individuals. A single bird was the most commonly observed drinking flock size, although the overall mean was 9.97 $\pm 0.6(n=807)$ (Figure 3).

Flock sizes were significantly different between morning and afternoon drinking sessions (Kruskal-Wallis $H=26.71, n=651,295, \mathrm{P}<0.001$ ). Overall, the larger flocks $(\bar{x}=13.5 \pm 0.9, n=457)$, were observed drinking in the early morning between o6hoo and o8h59 with smaller flocks $(\bar{x}=3.4 \pm 0.3, n=194)$ observed during the middle of the day between oghoo and $16 h_{59}$. There was a second, late afternoon peak between 17 hoo and 18 h59 ( $\bar{x}=8 \pm 1.2, n=156)$ (Figure 4 ).

Black-cheeked Lovebirds were cautious drinkers, particularly timid in the presence of non-avian (human, livestock and game) disturbance. Lovebirds generally approached a water source directly from the roost sites in the morning and from feeding sites in the afternoon. They arrived in small flocks, typically contact-calling on their approach, and then usually perched on the tallest tree or shrub within $15 \mathrm{~m}$ of the water. Time spent perched (typically in silence, except when answering the calls of

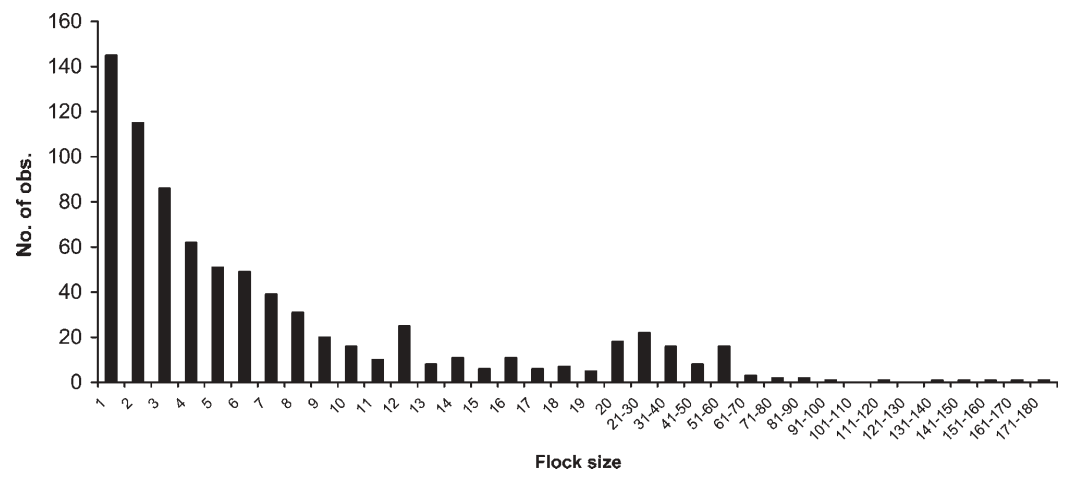

Figure 3. Frequency distribution of flock sizes of drinking lovebirds observed (mean $=10 \pm 0.6$, $n=807)$. 


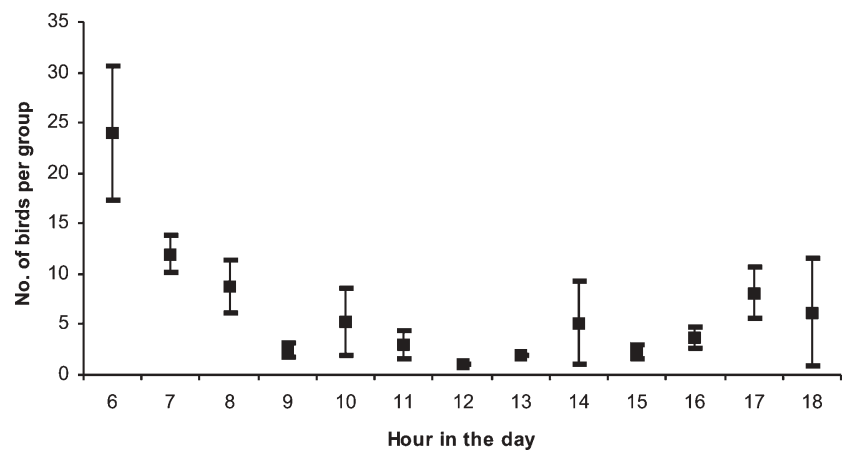

Figure 4. Mean flock size $\pm 95 \%$ confidence limits of drinking Black-cheeked Lovebirds by hour between February 1998 and December $2000(n=807)$ at the study site, in south-west Zambia, along the Machile and Sichifulo rivers.

approaching or passing lovebirds) was influenced by lovebird numbers in the locality and time of day. At isolated water sources, and/or when large flocks ( $>80$ ) gathered, early arrivals perched for up to Ioo min, waiting for all the birds to gather before drinking. Perched birds preened, allo-preened, sun-bathed and rested. When bird aggregations were smaller, or during non-peak periods, the birds perched in tall trees for only a few minutes, prior to flying down to a lower perch (typically a bush or small Acacia spp.) closer to the water's edge. From the lower perch they flew down to the water, landing just inside the water's edge so their feet were submerged. Small flocks nearly always drank in silence, in contrast to the larger gatherings that dropped to the water in noisy waves. Between drinking bouts, birds perched again either on the lower bush or in the original tall tree. After drinking, lovebirds departed in small groups, dispersing to either feeding sites in the morning or roost sites in the evening.

Black-cheeked Lovebirds ingested water by dipping their bills into the water, scooping or 'sipping' briefly, then raising their heads and tilting them slightly backwards, allowing water to run down their throats. The mean number of sips taken (between April and November) was $4.8 \pm 0.2(n=201)$. The temporal pattern (Figure 5$)$ shows a general increase in water intake per drinking bout towards the late dry season.

Occasionally, the lovebirds changed their drinking sites, a shift usually associated with a pool drying out. Although most birds adjusted immediately to the change, a few appeared 'disorientated', returning to the old water source contact-calling and perching for short periods. The 'confusion', however, lasted only a few days, after which birds arrived twice daily at the new drinking site.

Lovebirds bathed in the water, albeit infrequently. Bathing entailed lowering chests into the water accompanied by vigorous wing-flapping, followed by perching in the sun with drooped wings, fluffed body feathers, and rigorous preening.

Black-cheeked Lovebirds typically drank in single-species flocks, although they were observed drinking with 23 other species during $35 \%$ of the observations $(n=806)$ (Table 1$)$.

Most mixed flocks comprised either one (53\%) or two $(33 \%)$ other species, Southern Grey-headed Sparrows Passer diffusus and Long-tailed Starlings Lamprotornis mevesii being the most common. One hundred and fifteen bird species were recorded at Black-cheeked Lovebird water sources (Table 2). 


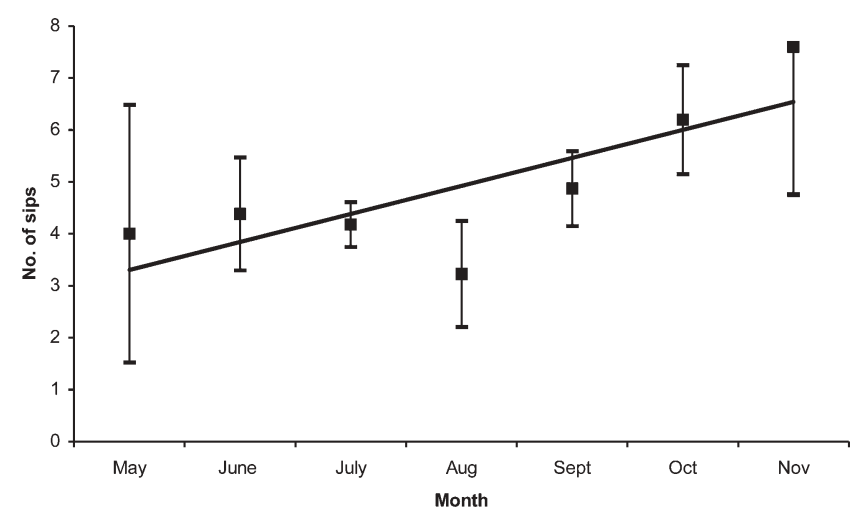

Figure 5. Mean number of sips $\pm 95 \%$ confidence limits taken by drinking Black-cheeked Lovebirds between May 1998 and November 2000 at the study site, in south-west Zambia, along the Machile and Sichifulo rivers. The unbroken line is represented by $y=-0.5404 x+2.7614$, with regression coefficient $\left(r^{2}\right)=0.6117$.

Table 1. Percentage occurrence of species commonly seen in mixed drinking flocks with Black-cheeked Lovebirds at the study site during $1998-2000$.

\begin{tabular}{llrr}
\hline Species Common name & Scientific name & $\%$ & $N$ \\
\hline Southern Grey-headed Sparrow & Passer diffusus & 24.2 & 103 \\
Southern Long-tailed Starling & Lamprotornis mevesii & 23.0 & 98 \\
Cape Turtle Dove & Streptopelia capicola & 12.7 & 54 \\
Red-billed Quelea & Quelea quelea & $7 \cdot 3$ & 31 \\
Meyer's Parrot & Poicephalus meyeri & 5.2 & 22 \\
Swainson's Francolin & Francolinus swainsonii & 5.2 & 22 \\
African Masked Weaver & Ploceus velatus & $4 \cdot 7$ & 20 \\
Greater Blue-eared Starling & Lamprotornis chalybaeus & 4.5 & 19 \\
Laughing Dove & Streptopelia senegalensis & 4.0 & 117 \\
Red-eyed Dove & Streptopelia semitorquata & 2.1 & 9 \\
Yellow-eyed Canary & Serinus mozambicus & 1.4 & 6 \\
\hline
\end{tabular}

Attacks (or at least assailment) by raptors (Shikra Accipiter badius, African Fish Eagle Haliaeetus vocifer, Lanner Falcon Falco biarmicus and Accipiter spp.) on Black-cheeked Lovebirds were observed on four occasions at water sources. Additionally, evidence of plucking (typical raptor behaviour prior to feeding on flesh) of a lovebird was found at Mabiya Pools, Kafue National Park.

\section{Discussion}

The need to drink

A close correlation exists between the diet and drinking habits of desert-adapted birds (Fisher et al. 1972). Since dry seeds contain little water, usually 8-12\% by weight (Fischer et al. 1972), granivorous birds tend to be particularly dependent on surface water throughout the year. As the primary diet of the Black-cheeked Lovebird comprises Jungle Rice Echinicholoa colona seeds with only a 9.5\% moist milled percentage (Warburton 2003, Warburton and Perrin in prep.), daily access to surface water is critical for the birds' survival. However, an Australian study (Macmillen and 


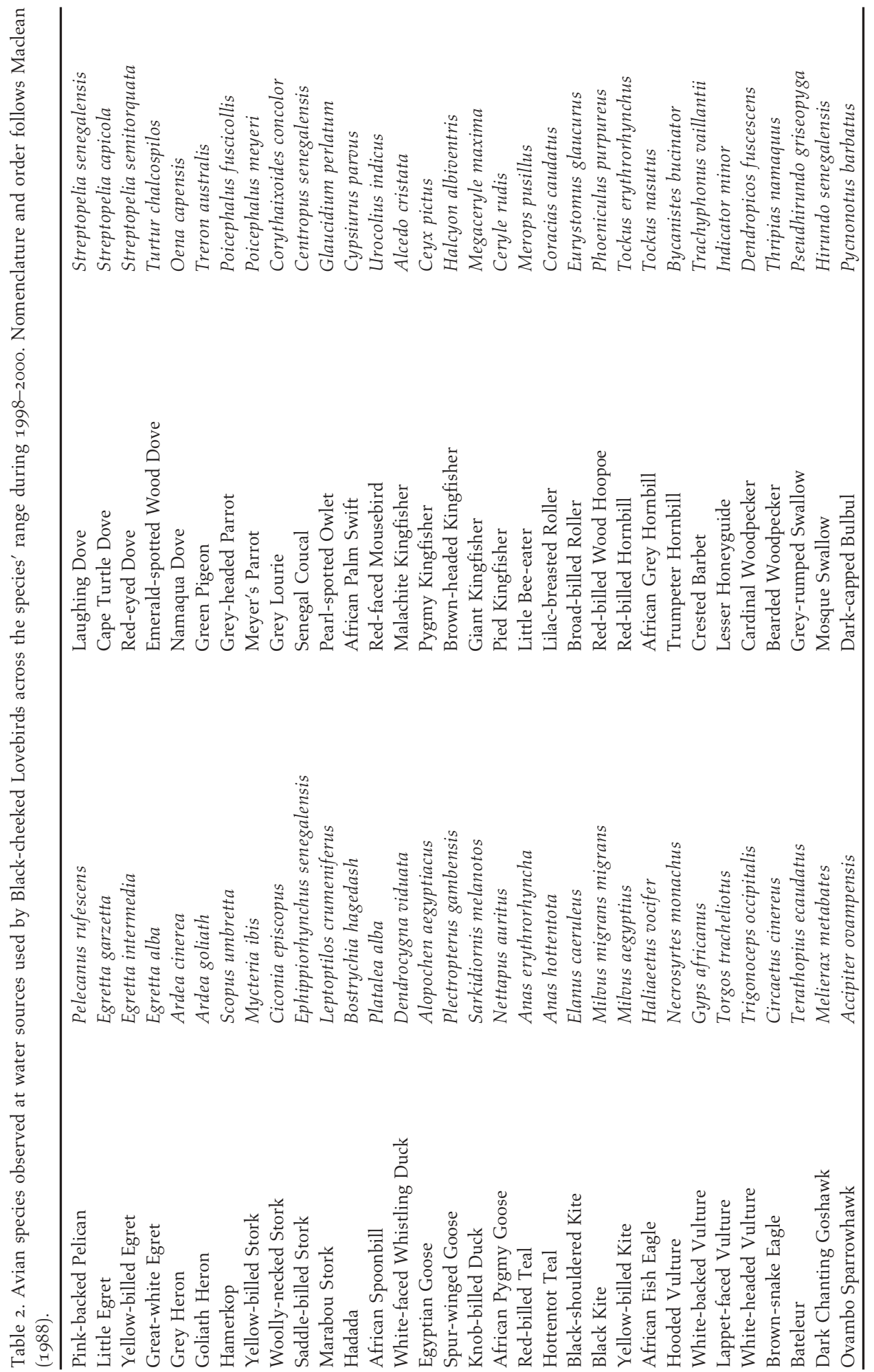




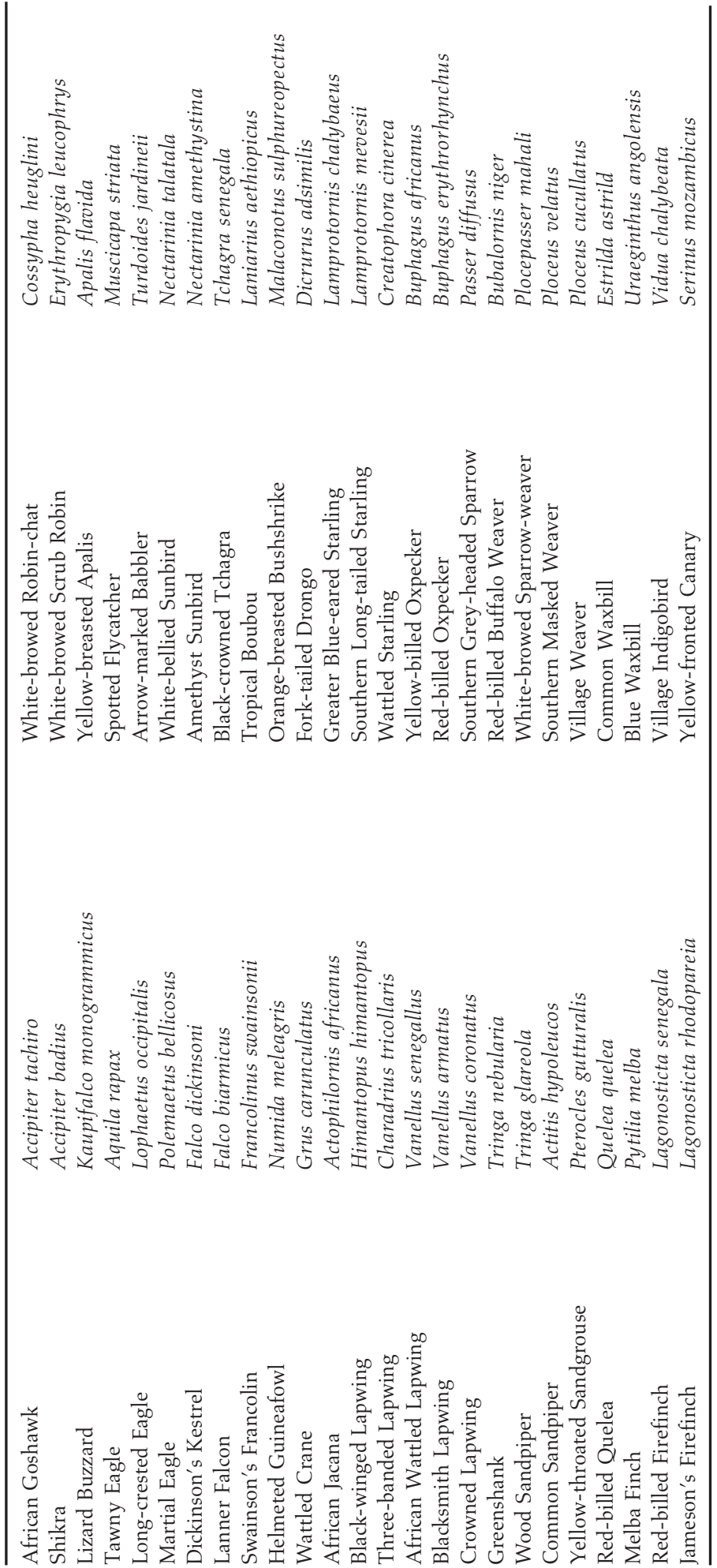


Baudinette 1993) showed that grass and herb seeds have higher carbohydrate and metabolic water production (MWP) yields than seeds of shrubs. This implies that small (< $<100 \mathrm{~g}$ ) granivorous parrots (such as the lovebirds in this study) that feed on grass seeds have better water regulation capacities than the larger-bodied parrots (e.g. Meyer's Parrots and Grey-headed Parrots) (Macmillen and Baudinette 1993).

\section{Daily drinking patterns}

The behaviour of the lovebirds while drinking is significant for their survival through preventing or reducing predation, and hence for their population viability and conservation. The birds are very cautious and vigilant when drinking, except when in large flocks, when reciprocal awareness and alarm calls reduce tension. Nevertheless, drinking bouts are short. Bathing, essential in maintaining feather condition and optimal flight, so necessary for predator avoidance, is interspersed with drinking. While lovebirds typically associate with conspecifics, they also frequently benefit from interspecies vigilance and alarm calls to avoid raptors common in the study area.

The drinking pattern of Black-cheeked Lovebirds displayed features common to those of other parrot species. Daily bimodal drinking bouts are typical of Bourke's Parrot Neophema bourkii, Mulga Parrot Psephotus varius, Port Lincoln Parrot Barnardius zonarius, Galah Eolophus roseicapillus and Pink Cockatoo Cacatua leadbeateri (Fisher et al. 1972); while drinking, although to a lesser extent. Some drinking between the peak bimodal periods is exhibited by Cockatiels Nymphicus hollandicus, Little Corellas C. sanguinea (Fisher et al. 1972) and Fisher's Lovebird A. fischeri (Moyer 1995). Avoidance of high daytime temperatures and intense solar radiation by drinking in the early and late hours, and by resting in the shade during mid-day hours, probably assist the Black-cheeked Lovebird's temperature regulation. Inter-drinking intervals may reflect a physiological difference in water requirements between large- and small-bodied parrots. Studies have shown that a small body size $(<100 \mathrm{~g})$ has a greater water regulatory efficiency budget than a large body size, and thus may be a derived physiological and evolutionary advantage (Macmillen and Baudinette 1993).

\section{Drinking habits in relation to water quality and pool disturbance}

Timing and extent of the last rainfall within a given locality determine water quality as evaporation rates concentrate electrolytes (Fischer et al. 1972). Although water potability was not measured in this study, late in the dry season Black-cheeked Lovebirds in south Kafue National Park were observed drinking in algae-ridden water pools containing dying fish, despite the presence of other cleaner water resources in the area, suggesting that water quality is not an important factor in Black-cheeked Lovebird water provision. Conversely, Lilian's Lovebirds A. lilianae in Luangwa valley, Zambia prefer clear, running water (Button 1953). While water quality may not be critical, disturbance caused by wild game or livestock trampling the water's edge was significant as the lovebirds rarely drank from such disturbed areas.

\section{Drinking habits and implications for species fitness}

Although natural predation of Black-cheeked Lovebirds was rarely observed at water sources, it is likely that drinking at isolated water sources in an arid region has several 
disadvantages, including a greater risk of predation, energy expenditure in travelling to and from water resources, and a loss of foraging efficiency due to competition for food resources around the water source (Fisher et al. 1972). Therefore, the physiological need to drink may be countered by the advantages of a granivorous diet (seeds as a food source being more dependable and in greater supply between seasons than other food items) (Fisher et al. 1972). Certainly, the food and nest-site requirements of the Black-cheeked Lovebird appear to be unlimited in terms of the species survival, with the exception of dry season surface water supply (Warburton 2003).

\section{Conservation implications}

Although the cause of the decrease in annual rainfall is unknown (attributable either to anthropogenic factors or global climate change) it is clear that the Black-cheeked Lovebird's range has been and is being reduced by gradual desiccation, and its distribution has been affected by the drying up of water sources (Dodman 1995). Rainfall data from three additional meteorological stations to those used in this study were analysed by Dodman (1995) who recorded a significant annual decline of $0.83 \%$ in rainfall between 1949 and 1994. Data processed in this study showed an annual decrease of $5 \mathrm{~mm}$ per year over the same time period, clearly demonstrating a natural desiccation over the lovebird's range. Experimental models suggest that declines in annual rainfall across the southern African region will continue, and by the $2080 \mathrm{~s}$ mean rainfall could average 5-18\% less than that experienced between 1961 and 1990 (Hulme 1995, Hulme and Sheard 1999).

The southern subpopulation of Black-cheeked Lovebirds, constituting approximately two-thirds of the total population (Dodman 1995, Dodman et al. 2000), has been affected both positively and negatively by various anthropocentric water-related activities. The major benefit has been increased surface water supplies, suitable for lovebird use, through the digging of pools and construction of small-scale dams in otherwise dry riverbeds. Similarly, in Australia, the spread of the pastoral industry into the arid interior has caused an increase in range and abundance of various bird species (Fisher et al. 1972), and in Namibia, Rüppell's Parrot Poicephalus rueppelli (del Hoyo et al. 1997) and the Rosy-faced Lovebird (Rowan 1983, Fry et al. 1988) have benefited from man-made water resources. It is highly probable that the Blackcheeked Lovebird would not survive along the Ngweze river (its type locality (Sclater 1906, Dowsett 1972) and its tributary the Lunungu without the digging of wells and provision of water for livestock.

Black-cheeked Lovebird dependence on man-made water resources in the (late) dry season renders the species susceptible to several threats. Although earlier studies (Kilmer 1994, Dodman 1995, Dodman et al. 2000) found lovebirds at Mutwanjili along the Ngweze river, the present study failed to locate any birds in this region. Interviews with local villagers confirmed the lovebird's absence, which was probably caused by reduction in surface water as a result of increased well depth and translocation of cattle watering sites (Warburton 2003).

Black-cheeked Lovebirds are cautious drinkers that abandon water sources subjected to regular disturbances at peak drinking periods. Also, their twice-daily habit of congregation at the same resource makes them vulnerable to capture. Some small pools are created and maintained, usually by young boys, for the sole purpose of 
attracting and catching birds (by snares placed around the water's edge) for consumption or local trading. Although lovebirds were not specifically targeted, if caught, they were readily consumed. While it was not possible to quantify the offtake of lovebirds, it is unlikely to represent a long-term effect on Black-cheeked Lovebird populations (Dodman 1995, this study), provided that consumption is confined to the local population, and other usable water supplies are available.

The recent establishment of hand-pumped bore-holes along the catchments of the Ngweze, Sichifulo and Machile rivers (L. Warburton pers. obs.) is likely to affect surface water availability during the dry season. Villagers pump water straight into containers with the small run-off usually channelled into a depression where livestock and the more human-habituated bird species (Blue Waxbills Uraeginthus angolensis, White-browed Sparrow Weavers Plocepasser mahali, Southern Grey-headed Sparrows Passer diffusus, and various weaver and starling species) drink. Given the high disturbance factor at these depressions, they are unsuitable water sources for lovebirds and other cautious avian drinkers (e.g. Meyer's Parrot Poicephalus meyeri and Greyheaded Parrot P. fuscicollis suahelicus) (L. Warburton pers. obs.). This decrease in available surface water may well deleteriously affect Black-cheeked Lovebird survival in this region.

\section{Conservation recommendations}

Regular monitoring (at least once every 5 years) of the Black-cheeked Lovebird's status across its range is recommended and should follow Dodman's technique (Dodman 1995, Dodman et al. 2000) of counting drinking birds at the height of the dry season, which also allows for water resource monitoring. The best agency to undertake such surveys would be the Zambian Ornithological Society, with assistance from the Zambian Wildlife Authority and the Livingstone Museum, all of whom were involved in the 1995 surveys and this study. Caution in interpreting Black-cheeked Lovebird numbers from water source counts is advised as the larger flocks congregating at water sources during the dry season probably comprise birds from a wide area, which may cause misinterpretation in terms of estimates of species abundance. More regular monitoring (annual) is recommended in the areas of greatest lovebird activity, such as the mid-Machile and Sichifulo rivers and the Mabiya pools region of south Kafue National Park. Education programmes, following on from the one instigated in September 2001 (Warburton 2001b,c), should be used to encourage local people, particularly schoolchildren, to create suitable lovebird drinking sites, and to minimize disturbances at existing sites during the early morning and late afternoon. Other water resources in the region should be made more lovebird-friendly by erecting perching material $15-25 \mathrm{~m}$ from the water's edge, although this might attract avian pests. During this study the lovebirds fed on two agricultural crops but there was no evidence to suggest a reliance on crops for survival, although the crop-ripening season coincided with the lovebird breeding season. The species is widely perceived as a crop pest, with $18 \%$ of seed heads of millet crops suffering $>20 \%$ damage during the ripening season (Warburton 2003). Local farmers attempted to protect their corps in a variety of ways; however, these were largely ineffective and rarely lethal to the lovebirds. The importance of elevating local tolerance of the species through education programmes must be highlighted. Particular attention should be directed at assessing the impact of pumped boreholes on surface water supplies. It is speculated that villages 
with pumps will reduce their water-source creation activities in riverbeds, thereby reducing water availability for lovebirds and other avian species, causing the birds to desert the area. It is also essential that the trade ban on wild-caught lovebirds is upheld as any resumption would be likely to lead to the rapid demise of the species given its highly localized range, predictable social gatherings and the general poverty of the human population in the area.

\section{Acknowledgements}

The project was predominantly sponsored by a grant from the Loro Parque Fundacion. Other funding was contributed by the NRF (National Research Foundation, South Africa), WCS (World Conservation Society), ZSCP (Zoological Society for the Conservation of Populations), WPT (World Parrot Trust), Zambezi Society (UK), IFAW, (International Federation of Animal Welfare) British Ornithologist's Union, Lovebird (1990) Society, Parrot Society, San Diego Zoological Society and the Conservation in Aviculture Society. British Airways Assisting Conservation and Station Africa also contributed. We are greatly indebted to our volunteer field assistants, Alex Mwenda, Aaron Muchindu and the headman and villagers of the region and the Zambian Wildlife Authority. Thanks go also to Ian Millar, Plant Protection Research Institute, Pretoria and Dr Ray Miller, University of KwaZulu-Natal, Pietermaritzburg, who assisted with invertebrate identification. Mike Bingham, Lusaka assisted with plant identification and Lynn Fish from the National Botanical Institute, Pretoria identified grass seeds. Nutritional analysis was conducted by the Department of Animal Science, University of KwaZulu-Natal, Pietermaritzburg.

\section{References}

BirdLife International (2000) Threatened birds of the world. Barcelona and Cambridge, U.K.: Lynx Edicions and BirdLife International.

Button, E. (1953) The Nyasa Rosy-cheeked Lovebird. North. Rhod. J. II(2): 37-42.

Cade, T. J. and Dybas, J. A. (1962) Water economy of the Budgerygah. Auk 79: 345-364.

Calder, W. A. (1981) Diuresis on the desert? Effects of fruit- and nectar-feeding on the House Finch and other species. Condor 83: 267-268.

del Hoyo, J., Elliot, A. and Sargatal, J. (1997) Handbook to birds of the world. Volume 4 (Sandgrouse to Cuckoos). Barcelona, Spain: Lynx Edicions.

Dodman, T. (1995) Status and distribution of the Black-cheeked Lovebird Agapornis nigrigenis. RSPB unpublished report:1-50.

Dodman, T., Katanekwa, V., Apsinwall, D. and Stjernstedt, R. (2000) Status and distribution of the Black-cheeked Lovebird Agapornis nigrigenis in Zambia. Ostrich 71: 228-234.

Dowsett, R. J. (1972) The type locality of Agapornis nigrigenis. Bull. Brit. Ornithol. Club 92: $22-23$.

Forshaw, J. M. (1989) Parrots of the world. Third revised edition. Newton Abbot, U.K.: David and Charles.

Fisher, C. D., Lindgren, E. and Dawson, W. R. (1972) Desert birds in relation to their ecology and abundance. Condor 74: 111-136.

Fry, C. H., Keith, S. and Urban, E. K. (1988) The birds of Africa. Volume 3. London: Academic Press.

Hulme, M., ed. (1995) Climate change and Southern Africa: an exploration of some potential impacts and implications in the SADC region. A report commissioned by WWF International and co-ordinated by the Climatic Research Unit, UEA. Norwich, U.K. 
Hulme, M. and Sheard, N. (1999) Climate change scenarios for Zimbabwe. Leaflet produced by the Climatic Research Unit, UEA and WWF International. Norwich, U.K.

Kilmer, A. (1994) Oxford University Lovebird Expedition. Unpublished report.

Klasing, K. C. (1998) Comparative avian nutrition. Cambridge, U.K.: Cambridge University Press.

Leppan, A. W. (1944) Birds of the Eastern Caprivi Zipfel. Ostrich XV(I): 20-43.

Maclean, G. L. (1988) Robert's birds of southern Africa. Cape Town, South Africa: The John Voelcker Bird Book Fund.

Macmillen, R. E. and Baudinette, R. V. (1993) Water economy of granivorous birds: Australian Parrots. Funct. Ecol. 7: 704-712.

Moreau, R. E. (1948) Aspects of the evolution in the parrot genus Agapornis. Ibis 90: 206-239, 449-460.

Moreau, R. E. (1945) The dwarf parrots of Tanganyika. Tang. Notes Rec. 19: 23-33.

Moyer, D. C. (1995) The status of Fischer's Lovebird Agapornis fischeri in the United Republic of Tanzania. Gland, Switzerland and Cambridge, U.K.: IUCN.

NPWS/JICA (National Parks and Wildlife Service/Japan International Cooperation Agency) (1999) Kafue National Park general management plan. Lusaka, Zambia.: NPWS departmental report.

Robbins, C. T. (1993) Wildlife feeding and nutrition. Second Edition. San Diego, CA, U.S.A.: Academic Press.

Rowan, M. K. (1983) The doves, parrots, louries and cuckoos of southern Africa. Cape Town, South Africa: John Voelcker Bird Book Fund.

Sclater, W. L. (1906) Agapornis nigrigenis, Sp.n. [The Black-faced Lovebird]. Bull. Brit. Bird Club 16: 61-62.

Warburton, L. (2001a) Black-cheeked Lovebirds in the hand. Safring News 30(1): 39-41.

Warburton, L. (2001b) Cikwele muikwa returns. Avizandum 13(11): 24-25.

Warburton, L. (2001C) Cikwele muikwa returns. Cyanopsitta 62: 10-11.

Warburton, L. (2002) Black-cheeked Lovebirds: Africa's most threatened lovebird. Africa Birds and Birding Magazine 7(I): 52-59.

Warburton, L. (2003) The ecology and conservation biology of the Black-cheeked Lovebird Agapornis nigrigenis in Zambia. Ph.D. thesis, University of Natal, South Africa.

LOUISE S. WARBURTON and MICHAEL R. PERRIN

Research Centre for African Parrot Conservation, School of Biological and Conservation Sciences, University of KwaZulu-Natal, Private Bag Xo1, Scottsville 3209, South Africa. E-mail:Perrin@ukzn.ac.za, Tel: +33260 5118,Fax: +332605105

Received 22 July 20004; revision accepted 21 April 2005 